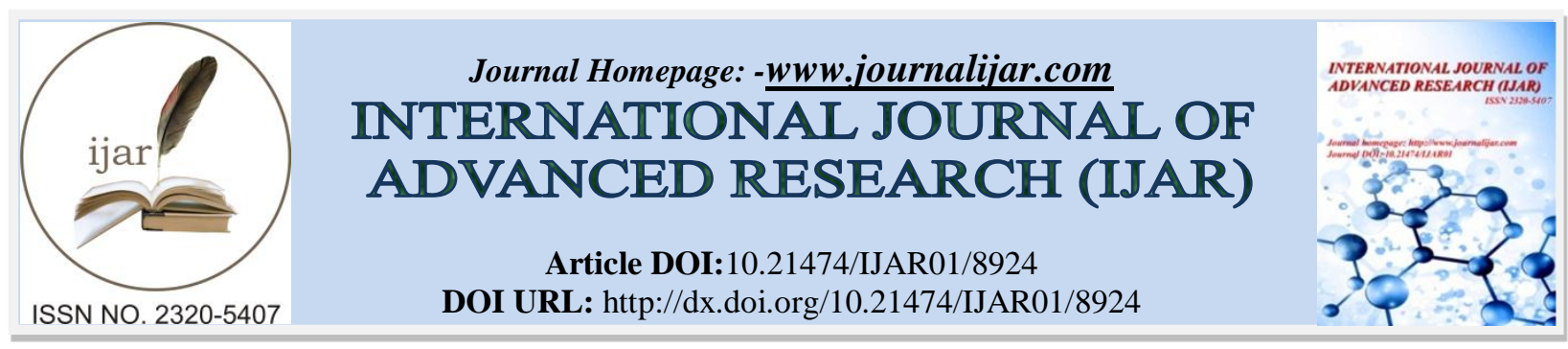

RESEARCH ARTICLE

\title{
SPIGELIAN HERNIA: A CASE REPORT.
}

\section{Abdessamad EL Kaoukabi, Hicham Krimou, Mohamed Menfaa, Fouad Sakit and Abdelkrim Choho. General surgery department, Moulay Ismail Military Hospital, Meknes.}

\section{Manuscript Info}

Manuscript History

Received: 21 February 2019

Final Accepted: 23 March 2019

Published: April 2019

Key words:-

Green's function, Fick's Law, Thermal

diffusivity, Thermal conductivity.

\begin{abstract}
Introduction: The Spigelian hernia or lateral ventral hernia is an unusual dehiscence appearing on Spigel's line or semi-lunar fascia. It is a rare clinical entity, represents 0.10 to $1 \%$ of hernias. Also, it seemed appropriate to report this case collected in the visceral surgery department of the Moulay Ismail military hospital. Patient and observation: We report the observation of a 48 -year-old patient with no particular history. with a progressive right umbilical swelling, a Spigelien hernia was suspected on clinical examination, and the diagnosis of left anterolateral forceps was retained on abdominal computed tomography. Prolene plaque herniation was performed and the operative follow-up was simple. Conclusion: Spigelien hernia is a rare condition; its clinical diagnosis can be difficult. It is asymptomatic in $90 \%$ of cases and its positive diagnosis is radiological. The risk of significant strangulation requires surgical treatment once the diagnosis is confirmed.
\end{abstract}

Copy Right, IJAR, 2019,. All rights reserved.

\section{Introduction:-}

The reputation of the rarity of the Spigelien hernia is known, it constitutes 0.1 to $1 \%$ of the the abdominal wall hernias [1]. It is a hernia generally located in para and umbilical, located in the semi-lunar line (aponevrosis of the small oblique and transverse). It may contain epiploon, hail and colon and its contents may be reducible or not. His positive diagnosis is radiological and surgery is his only treatment. In the light of an observation and a review of the litterature, the purpose of our work is to highlight the diagnosis difficulties and the different therapeutic modalities of this pathology.

\section{Patient and observation:}

We report the case of a patient aged 48, mother of 5 children, obese, having for 3 years a right umbilical mass, gradually increasing in volume, without transit disorder and without altering the general condition. On examination it was a mass about $14 \mathrm{~cm}$ in diameter, soft, non-painful and non-reducible, with no inflammatory sign opposite, evoking in the first place a lipomatous proliferation. Ultrasound showed sub-umbilical muscular dehiscence at the semi-lunar spiegel line with presence of the hernia sac containing the large omentum.

Surgical exploration revealed a spigelien hernia containing large viable epiploon (Figure 1), the treatment consisted in a reduction of the hernia with a parietal cure per nonabsorbable plate (Figure 2). The postoperative course was simple.

Corresponding Author:-Abdessamad EL Kaoukabi.

Address:-General surgery department, Moulay Ismail Military Hospital ,Meknes. 


\section{Discussion:-}

The semi-lunar line was described for the first time by Adriaan van der Spieghel in 1645 [2], and corresponds to the junction at the lateral edge of the right muscles of the abdomen of the fascia of the large muscles. It is a rare but not exceptional pathology (less than 1000 publications worldwide) [3]. It usually occurs after the age of 40 [4] and is most often found below the umbilical level by dehiscence of the fascia of the transverse and internal oblique muscle, which appear to be weaker in the vicinity of the arched line. The main risk factors are obesity and pregnancy.

The clinical diagnosis of spiegel hernia is often made difficult by obesity, either when the hernia is small it is barely palpable, or in case of a large hernia protruding under the skin it can be confused with a lipoma as in the case of our observation or with an intra-abdominal tumor. It is estimated that around $50 \%$ of patients with spiegel hernias did not have a correct preoperative diagnosis [5].

The abdominal CT remains the key examination for the confirmation of the diagnosis with a great sensitivity, it allows to see the muscular dehiscence and the contents of the hernial sac [6]. As any herniation of the ventrolateral wall of the abdomen the risk of incarceration or strangulation is important, and can go up to 32\% [7], for which reason, the surgical treatment must be established as quickly as possible. possible. The parietal treatment by prosthetic plaque is the treatment of choice [6], the laparoscopic way in addition to its diagnostic interest had proved its effectiveness in the treatment of this type of hernia $[3,8]$, the conventional way is still in place especially in large hernias.

\section{Conclusion:-}

The spigelien hernia is a rare disease in young adults, the clinical diagnosis is sometimes difficult, but the radiological examinations and above all the scanner keeps a great sensitivity for the confirmation of the diagnosis. The risk of significant strangulation requires surgical treatment once the diagnosis is confirmed.

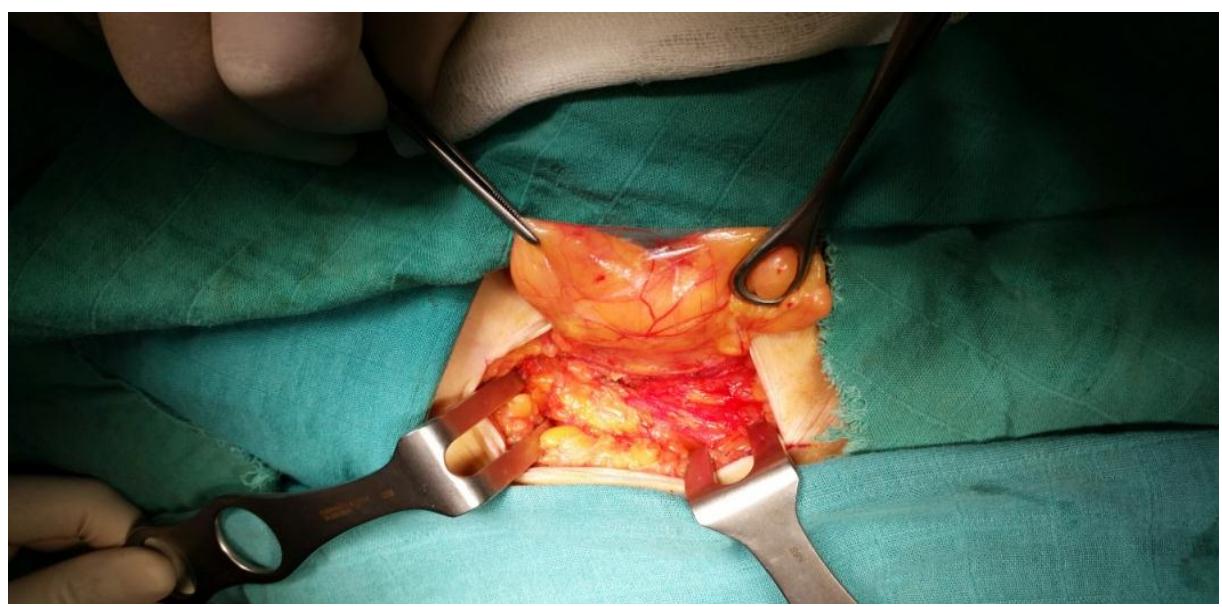

Figure1:-Spigelien hernia containing large epiploon

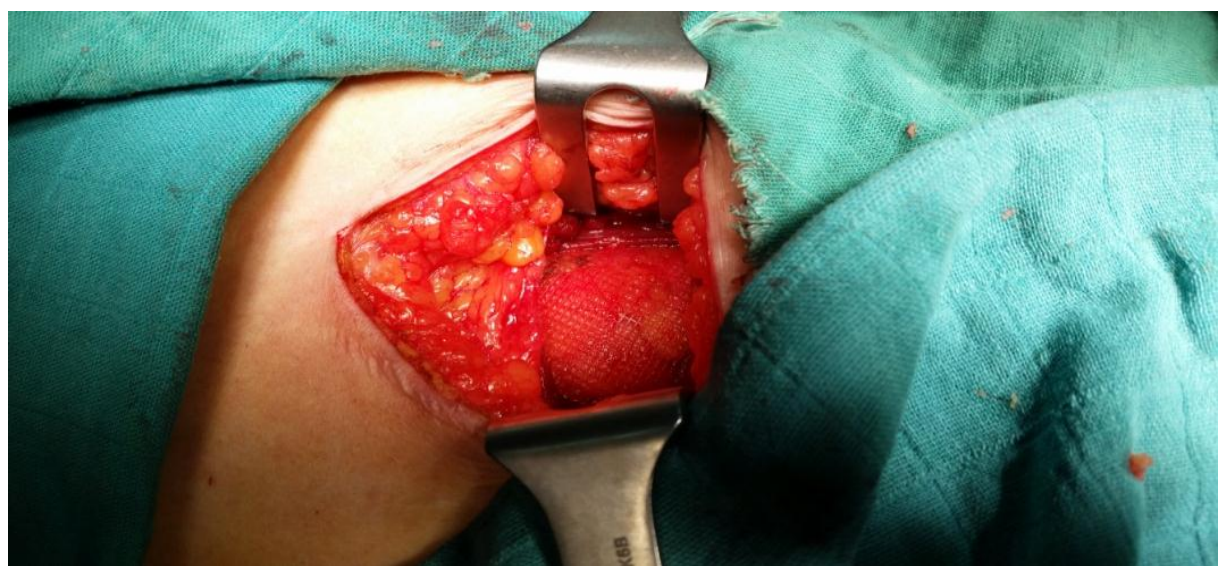

Figure 2:-Placement of a non-resorbable prosthetic plate 


\section{References:-}

1. Spangen L. Speighe lian hernia. In: Nyhus L, Condom RE eds. Hernia

2. A. van den Spiegel: Opera quae extant omnia.Ex recensione Joh.Antonidae vander Linden

3. García-Molina F, Ortegón-Castellano B, Franco-Osorio JD, Domínguez-Adame-Lama E, Gil-Quirós FJ.Tratamiento slaparoscópico de la hernia de Spiegel.Cádiz Cir Esp.2002;71(4):207-9

4. Spangen L. Spigelian hernia. En: Nyhus LLM, Condon R, directors. Hernia

5. Eubanks S. Hernias. En: Sabiston DC, Lyerly HK, editores. Tratado de patología quirúrgica

6. Antonio Carbonell-Tatay, Francisco Javier Landete Molina. Hernia de Spiegel. Arch Cir Gen Dig. 200410 Octubre

7. Pera C. Cirugía, fundamentos y opciones técnicas. Barcelona: Salvat.1983; 569-597

8. Kasirajan K, López J, López R. Laparoscopic technique in the management of spigelian hernia. J Laparoendosc Adv Surg Tech A. 1997 Dec; 7(6):385. 